\title{
THE CHALLENGES OF SMART TOURISM: A CASE OF BUCHAREST
}

\section{Gabriel-Cristian Sabou*}

Bucharest University of Economic Studies, Romania

E-mail: gabriel.sabou@com.ase.ro

\section{Irina Maiorescu}

Bucharest University of Economic Studies, Romania

E-mail: irina.maiorescu@com.ase.ro

\section{(Received: March 2020; Accepted: May 2020; Published: June 2020)}

\begin{abstract}
The advancement of technology makes smart devices and their applications ever more popular and complex. Tourism is an area where varied and numerous services are required, hence this diversity resulted in a multitude of smart applications and smart systems designed to enhance tourist's satisfaction. The present paper investigates the concept of Smart Tourism in the scientific literature and how it can be applied for mobile applications, with particular focus on the most popular Smart Tourism apps for Bucharest. Following the analysis of these apps according to the theoretical framework applied, recommendations for improvement of Bucharest Smart Tourism mobile applications are provided.
\end{abstract}

Keywords: Smart Tourism, mobile applications, data

JEL Codes: L83, M15, Z32

\section{Introduction}

More and more tourists make use of Smart Tourism, in order to enhance the value of their touristic experiences they choose. This form of tourism is seen as an informational service and it is based on technologies designed to support the individual tourist ( $\mathrm{Li}$ et al., 2017). Kontogianni and Alepis (2020) consider that Smart Tourism is more about the interaction between the physical world and the digital one, with the help of social media, cloud computing and Internet of Things (IoT).

\footnotetext{
*Corresponding author: Gabriel Cristian Sabou.E-mail: gabriel.sabou@com.ase.ro

Copyright (C) 2020 The Author(s). Published by VGWU Press

This is an Open Access article distributed under the terms of the Creative Commons BY 4.0 license (Creative Commons - Attribution 4.0 International - CC BY 4.0) which permits unrestricted use, distribution, and reproduction in any medium, provided the original author and source are credited.
}

70 sciendo Studia Universitatis "Vasile Goldis" Arad. Economics Series Vol 30 Special Issue 2/2020 ISSN: 1584-2339; (online) ISSN: $2285-3065$ 
Sabou, G.C., Maiorescu, I., (2020)

The challenges of Smart Tourism: a case of Bucharest

Regardless of definitions, one common trait is found: Smart tourism is based on digital data about touristic services and destinations useful to their users. Preservation of user privacy must be ensured due to the fact that the use of the Internet and various mobile applications leave digital marks about the user's behavior, the visited places, preferences, etc. (Demunter, 2017). The EU General Data Protection Regulation (Intersoft Consulting, 2020) stipulates that the data management must meet strict standards, so it is essential that there are confidentiality rules and that users are well informed about the personal data they provide.

This recent regulation posed challenges in the way internet-based applications made use of the information tracked and used for understanding user's behavior in various areas of activity, the tourism sector, of course, is included. Smart applications and systems designed for tourists have to understand users' needs and behavior and to adapt the offered services to their particularities.

The paper starts with analyzing the scientific literature concerning the dimensions and challenges of Smart Tourism, focusing next on mobile Smart tourism applications. An analysis of three different smart mobile applications created for Bucharest is made, taking into consideration the necessary key elements for their functionality, as identified in the literature review. The recommendations for improvement or for new Smart application development, as resulted from the analysis, are made in the final part of the paper.

\section{Literature review}

\subsection{The concept of Smart Tourism}

Along time, researchers have defined the concept of Smart tourism in different manners. The Organization for Smart Tourism in the U.K. considers that the use of technology in the tourism sector makes the tourism "digital" or "smart" (Smart Tourism, 2020), nevertheless, we consider it to be too general. The EC sees in its initiative "European Capital of Smart Tourism" a smart tourism destination as a "destination facilitating access to tourism and hospitality products, services, spaces and experiences through ICT-based (Information and communications technology) tools" (European Capital of Smart Tourism, 2020). According to Gretzel et al. (2015), smart tourism implies three components: Smart experience, Smart Business Ecosystem and Smart Destination, all based on Information and Communications Technologies (ICT). The collection, exchange and processing of data take place through these components.

The structure of an efficient Smart Tourism system should be based at least on:

- data deriving from human input and sensors, 
Sabou, G.C., Maiorescu, I., (2020)

The challenges of Smart Tourism: a case of Bucharest

- a platform that provides processing and analysis of the retrieved data, as well as communication to the cloud,

- the resulting personalized services addressing tourist needs ( $\mathrm{Li}$ et al., 2017; Kontogianni \& Alepis, 2020).

Xiang and Fesenmaier (2016) consider that big data analytics must be used for smart tourism development and smart tourism requires a "creative computing" (Zhang et al., 2018).

A research performed by Kontogianni and Alepis (2020) identified the most frequent areas of interest for researchers of Smart tourism, by reviewing the scientific literature in this field. These identified clusters are: Privacy Preserving, Context Awareness, Cultural Heritage, Recommender Systems, Social Media, Internet of Things, User Experience, Real Time, User Modelling, Augmented Reality and Big Data.

Privacy Preserving is a very important aspect which must be taken into consideration in the process of conception of a Smart Tourism application because Smart Tourism requires retrieving and processing as much as possible information about tourist preferences, interests, geographical location, social behavior, education, etc, data protection is essential. Of course, this data can be willingly given access to by tourists themselves, but it can also be observed data, gathered from $3{ }^{\text {rd }}$ party digital sources. As such, The EU General Data Protection Regulation (GDPR) must be carefully implemented when designing applications for Smart tourism. Thus, developers must take into consideration privacy policies and certifications, the algorithms for ensuring anonymity within application wherever possible and data protection impact assessment (DPIA). One possible solution for storing and encrypting sensitive data inside such a Smart tourism application is using blockchain (Nam et al., 2019).

Related to Context Awareness, the research emphasizes that only relevant contextual factors should be taken into consideration when designing Smart tourism applications (Braunhofer \& Ricci, 2017; Kontogianni \& Alepis, 2020).

The customs, tradition, folklore and cultural particularities of an area - its cultural heritage, must be taken into consideration in Smart Tourism by offering tourists relevant cultural heritage information related to their trip, and by recommending them various points of interest along their route. The digitalization of cultural heritage assets is required, most often through Geographical Information Systems (GIS) (Campanaro et al., 2016) and suggestions for visiting these should rise, according to tourists' relevant contextual factors.

Considering the advancement of technology and the increasing amount of information available, recommendations and decision making about touristic destinations are very challenging processes. Recommender systems in tourism are

72 Sciendo Studia Universitatis "Vasile Goldis" Arad. Economics Series Vol 30 Special Issue 2/2020 ISSN: 1584-2339; (online) ISSN: 2285 - 3065

Web: publicatii.uvvg.ro/index.php/studiaeconomia. Pages 70-82 
Sabou, G.C., Maiorescu, I., (2020)

The challenges of Smart Tourism: a case of Bucharest

designed to facilitate the seeking and filtering of relevant information for tourists, helping them to make decisions about various touristic destinations, services and facilities (Gavalas et al., 2014).

Social media provides a huge amount of data regarding users' profiles (Brandt et al., 2017), their traveling behavior and inclinations generated by their social interaction, uploading images and locations check-in. The challenge is to make use of such rich information, without trespassing data privacy rules, so that tourists' preferences may be better understood. Embedded consented connection within the app with various social media channels provides useful insights for modeling behavior and recommending touristic services

The term Internet of Things was introduced by Kevin Ashton (MIT) in 1999. IoT was seen as an anytime-anywhere connecting network that identifies, locates, manages and monitors smart objects (Al-Turjman, 2019).

IoT enables the intelligent connection of objects and places to a smart technological environment, allowing real-time data retrieving and, consequently, real-time decision making about touristic activities. IoT in tourism offers more than support for tourists in suggesting lighter traffic routes, free parking places, available hotels and restaurants, less crowded points of interest, less polluted areas, etc.; it also provides authorities with information about the touristic assets they manage, about infrastructure and the efficacy of their implemented measures.

The main objective in designing the Smart Tourism Applications should be enhancing user's satisfaction in using it (Buhalis \& Amaranggana, 2015).

User's experience refers to both its utility and its ease and pleasure of use. Though difficult to achieve, the possibility of customizing the app is a characteristic that significantly enhances user's experience of smart tourism.

Real-Time cluster refers to recording through mobile and Global Positioning System (GPS) technology and transmitting both real-time location and data about tourists' experiences, preferences and behavior.

User Modeling starts with acquiring data about tourists' behaviors and interests, as these are the basis for future modeling of their touristic destination decision making processes. The data collected can be explicit - directly transmitted by the individual to the application, but also implicit - coming from other sources, such as sensors, social media, smart devices, etc. This understanding and forecasting of users' behaviors are vital, as it provides the basis for offering context-relevant information, at the right time, in the right manner. It allows for designing the features and contents of the Smart Tourism application accordingly.

Augmented Reality technology refers to the "augmentation" of real-world landscapes, buildings, objects with the help of technology. Visual, audio, sometimes tactile representations of the virtual objects are obtained on computers, smartphones, pads or other devices. In this way, Augmented Reality brings an 
Sabou, G.C., Maiorescu, I., (2020)

The challenges of Smart Tourism: a case of Bucharest

enhanced understanding of the environment or objects. In tourism, Augmented Reality facilitates seeing and learning about unknown places, missing or partially destroyed heritage assets, increasing the overall satisfaction of their touristic experience (Demir \& Karaarslan, 2018). Because it requires the interpolation of large amounts of data, in order to provide the digital representation of reality, this useful characteristic of Smart tourism should be carefully used within applications. Its injudicious use may overload the smart tourism system, resulting in blockages, delays and overall negative user experience.

Big Data is important for understanding tourists, predicting their behavior and modeling their future experiences.

\subsection{Smart Tourism and smartphones applications}

In order to develop smart tourism as efficiently as possible, numerous actors involved in the tourism field, as well as communities who wanted to promote their city or a certain destination, tried to find solutions using ICT resources. Taking into consideration the nowadays strong attachment of people to their smartphones and the fact that mobile devices are accompanying users anytime and everywhere, including along their travels, smartphones are useful resources for smart tourism solutions. The sensors and applications included in these devices provide important information about the preferences of their users, creating premises for better personalization of services from Smart Tourism systems (Yang, 2018; Kontogianni \& Alepis, 2020).

By looking at the focus of the scientific literature in the field of Smart Tourism, as presented before, we can remark that several clusters actually lead to a single common need. As such, we suggest that when designing a mobile application for Smart Tourism, the following issues must be particularly taken care of:

- Privacy policy and security methods for hosting and processing the information retrieved.

- Real Time data reception and analysis.

- IoT integration.

- Dynamic personalization of app' s content and features, according to users' needs as retrieved from various data sources (Social Media, Sensors, IoT, Internet, user direct input etc).

- Recommender system according to users' needs as retrieved from various data sources (Social Media, Sensors, IoT, Internet, user direct input etc).

- Augmented reality.

- Cultural Heritage.

Mobile applications' degree of smartness varies, depending on the complexity of the embedded software but also, on the capabilities of the smartphones. An

74 sciendo Studia Universitatis "Vasile Goldis" Arad. Economics Series Vol 30 Special Issue 2/2020 ISSN: 1584-2339; (online) ISSN: $2285-3065$

Web: publicatii.uvvg.ro/index.php/studiaeconomia. Pages 70-82 
Sabou, G.C., Maiorescu, I., (2020)

The challenges of Smart Tourism: a case of Bucharest

application requiring a permanent connection to the internet, transmitting and receiving data - especially video data for bringing out an Augmented Reality object will need processing performance, display and powerful battery life to ensure a good experience throughout a touristic tour, along the day. In order to offer a solution to this issue and support Smart Tourism, for example, Barcelona offers USB ports for charging mobile phones for people waiting in the bus shelters (Lee et al., 2017).

The challenge for developers is finding the balance between those services really required by a positive Smart Tourism Experience, technological costs and limitations.

\section{Analysis of Smart Tourism Apps for Bucharest}

\subsection{A presentation of Smart Tourism Apps for Bucharest}

\section{Bucharest City App}

One of the most known and popular mobile applications for tourists and the community in Bucharest, is the Bucharest City App. The application (Bucharest City App, 2020) is structured into more sections: Locations, Explore Bucharest, Fun \& Relax, Four Tourists and Useful Information.

Regarding Locations section, the application offers to the user the possibility to choose from a wide variety classified in the following categories: Restaurants; Cafes and Teahouses; Pubs and Bars, Clubs, Fast Food, Bakeries and Confectioneries. When choosing a location, for example, a restaurant, the user has access to more information about it, namely: the name of the restaurant, the operating hours, the website address, the Facebook page address, a short description, representative images, its position on Google maps and the possibility of indications to get to that place. The location recommendation is made according to the place where the user is at that time.

Explore Bucharest has 4 categories: Top 10 Attractions, Historical Buildings, Free Attractions and Panoramic Views.

Fun \& Relax, another section of Bucharest City App which gives the users the possibility to find SPA \& Beauty, Sport \& Adventure, Bike Rental and shopping places.

The data from For tourism section is structured in 8 categories: Romania landmark, Tourist routes, Museums, Transport, Weekend break, Bus lines, Bike rentals and Accommodation.

Also, the application recommends events that take place in Bucharest, it offers information about the air quality in Bucharest and provides also the map of the underground.

The application is available for smartphones with Android and iOS operating 
Sabou, G.C., Maiorescu, I., (2020)

The challenges of Smart Tourism: a case of Bucharest

systems, but it is also available as a web application.

Questo - self-guided interactive tours

Another way to get to know Bucharest, being both within the reach of locals and tourists, is represented by the digital tours of Questo. For Bucharest there are 6 such tours (Questo, 2020):

- Bucharest Walking Tour \& City Game: Old Town Secrets \& Hidden Gems

- Communist Bucharest Walking Tour: Communism in Romania

- Haunted Bucharest Walking Tour \& City Game: Ghosts and Horror Stories

- Bucharest Walking Tour \& City Game: The hidden gems of Bucharest

- Dracula in Bucharest Walking Tour \& City Game

- Seven Wonders of Bucharest.

Through these tours authentic experiences are created for tourists and locals, using stories that include play and discovery elements. To complete such a route, users receive a unique starting point in the city, and once they get there, the application sends them a first hint, which they must solve in order to discover the next place on the route. Each time they solve a hint and discover a new place, users receive through the application the story of that place. Then a new clue follows, and the process is repeated until the end. Players describe Questo as 'a mix of treasure hunting, escape room through the city, free walking tour and race around the world' (Google Play, 2020a).

\section{Bucharest Offline City Map}

An alternative for tourists who do not want or do not have the opportunity to use internet data when visiting the capital of Romania is the application Bucharest Offline City Map (Figure 1).
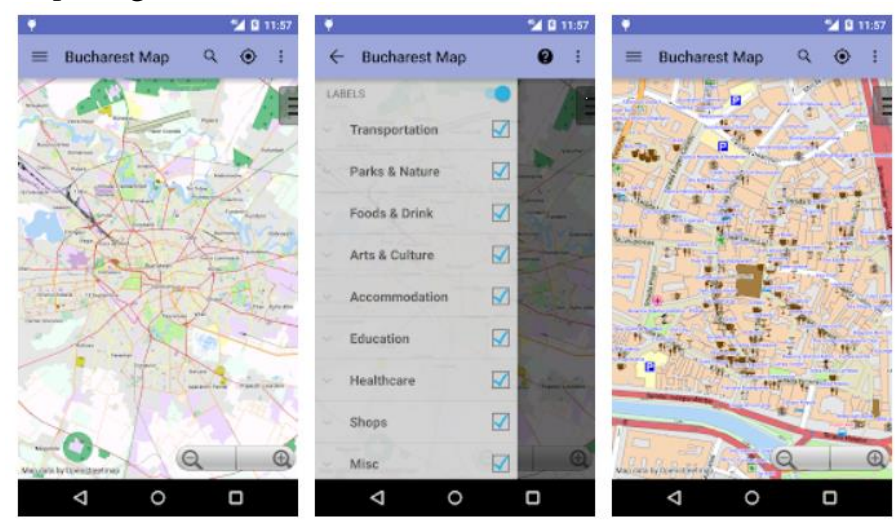

Figure 1 Bucharest Offline City Map

Source: Google Play, 2020b 
The mobile app offers an interactive map of Bucharest and has a search index for locating streets and other points of interest such as museums, restaurants, hotels, parks and nature, etc. The most important aspect of the application is that, after the installation, it does not require the internet for displaying the map or the other points of the interest, because map data comes from the OpenStreetMap project (Google Play, 2020b).

\subsection{Methodology and empirical data}

Starting from the research conducted by Kontogianni \& Alepis (2020) and taking into account the key concepts, we analyzed the three mobile applications described above - applications that are closely related to the concept of Smart Tourism.

About Real Time data usage, only the first two applications, Bucharest City App and Questo rely on this feature and base their services on information provided by users' mobile phones, such as location, temperature, etc.

Recommender system concept is used just by Bucharest City App. Questo app was designed as a story of a predetermined route, and the user will discover only the recommended objectives related to the theme of the rout, therefore we can say that it provides recommendations, but not those dynamic, personalized according to tourist's particular behavior.

From our research, we can state that real-time data and recommendations are based on location and user's own inputs (selecting desired categories), but they are not connected to a IoT network, neither they predict behaviors and recommend places based on data analysis. All applications allow filtering and some personalization, according to users' preferences and the Cultural Heritage approach is also identified in all three applications.

All these applications have a privacy policy declaration embedded. The most secure in terms of real-time personal data security is Bucharest offline app, as the possibility of a third party interceptor in the Internet communication protocols between mobile devices and servers is removed.

A synthesis of the analyzed characteristics found in the three applications is presented in Table 1 below. 
Sabou, G.C., Maiorescu, I., (2020)

The challenges of Smart Tourism: a case of Bucharest

Table 1 Comparative analysis of the applications according to Smart Tourism characteristics

\begin{tabular}{|l|c|c|c|}
\hline \multicolumn{1}{|c|}{ Characteristics } & $\begin{array}{c}\text { Bucharest } \\
\text { City App }\end{array}$ & $\begin{array}{c}\text { Questo - } \\
\text { Bucharest } \\
\text { walking } \\
\text { tours }\end{array}$ & $\begin{array}{c}\text { Bucharest } \\
\text { Offline } \\
\text { City Map }\end{array}$ \\
\hline $\begin{array}{l}\text { Privacy policy and security methods for hosting } \\
\text { and processing the information retrieved }\end{array}$ & $\mathrm{X}$ & $\mathrm{X}$ & $\mathrm{X}$ \\
\hline Real Time data reception and analysis & $\mathrm{x}$ & $\mathrm{X}$ & $\mathrm{O}$ \\
\hline IoT integration & $\mathrm{O}$ & $\mathrm{O}$ & $\mathrm{o}$ \\
\hline $\begin{array}{l}\text { Dynamic personalization of app's content and } \\
\text { features, according to users' needs as retrieved } \\
\text { from various data sources (Social Media, Sensors, } \\
\text { IoT, Internet, user direct input etc.) }\end{array}$ & $\mathrm{p}$ & $\mathrm{p}$ & $\mathrm{p}$ \\
\hline $\begin{array}{l}\text { Recommender system according to users' needs } \\
\text { as retrieved from various data sources (Social } \\
\text { Media, Sensors, IoT, Internet, user direct input } \\
\text { etc.) }\end{array}$ & $\mathrm{p}$ & & $\mathrm{O}$ \\
\hline Augmented reality & $\mathrm{o}$ & $\mathrm{O}$ & $\mathrm{X}$ \\
\hline Cultural Heritage & $\mathrm{x}$ & $\mathrm{X}$ & $\mathrm{x}$ \\
\hline
\end{tabular}

Legend: $\mathrm{x}$ - the characteristic is present; $\mathrm{p}$ - the characteristic is partially present; $\mathrm{o}-$ the characteristic is not present

Source: author's view

\section{Conclusions}

Smart Tourism developed along with technological advances in society. It has a great contribution to the nowadays touristic experience and one of its most popular forms comes from dedicated mobile applications. Our research in the literature review has identified as very important aspects to be taken into consideration when designing an application, the following:

- Privacy policy and security methods for hosting and processing the information retrieved.

- Real Time data reception and analysis.

- IoT integration.

- Dynamic personalization of app's content and features, according to users' needs as retrieved from various data sources (Social Media, Sensors, IoT, Internet, user direct input etc.).

- Recommender system according to users' needs as retrieved from various data sources (Social Media, Sensors, IoT, Internet, user direct input etc.).

- Augmented reality.

- Cultural Heritage. 
Sabou, G.C., Maiorescu, I., (2020)

The challenges of Smart Tourism: a case of Bucharest

GDPR provisions may make difficult the retrieving and processing of personal data about users. Consequently, application developers are challenged to create those accepted by user solutions that will bring enough relevant information to allow for modeling and for enhancing user Smart Tourism experience (such as real-time accurate reports, valuable personalized recommendations, the possibility of connecting through the app to a IoT network etc.).

It is difficult to encompass in one mobile application all these aspects because higher complexity generates higher costs and requires more resources both for the developer and for the user. Therefore, an equilibrium must be met.

Our analysis focused on the three most popular applications for Smart Tourism in Bucharest, taking into consideration the relevant issues found in the scientific literature. The results show that none of these characteristics are fully present in these mobile applications, some of them lacking entirely.

By analyzing these popular smartphone tourism applications, we can state that there is a place for improvement, in order to ensure a Smart Tourism really dynamic and adapted to the user's behavior and needs. As such, our recommendations for improvement refer to:

- Implementation within the application of audio guides, in different languages.

- Inclusion of facilities that allow restaurants, museums and various other places of interest located in the surrounding area to communicate to the tourists their available offers; the tourist should have the possibility to make a reservation directly through the application. These choices, more than enhancing the user experience of Smart Tourism, will contribute with data to building and modeling tourist's profile.

- Allowing the user to authenticate in the application and with the account created on a certain social network. In this way, the application will have the opportunity to analyze the client's profile according to his preferences and will be able to offer recommendations based on his profile.

- When creating the application, it is also necessary to take into account the subsequent integration of some IoT components in order to solve various situations encountered by tourists during their visit to various points of interest. For example, if a touristic objective is very visited (like famous museums), in front of it having been formed queues, installing sensors in the waiting space that communicate with the mobile application would provide the user with the waiting time. If the waiting time is too long, the application may recommend other points of interest in the area.

- The graphical interface of the application should be intuitive and designed in such a way that it can be adapted to all age categories of users, even for 
he elderly or for those who do not have highly developed digital skills.

- Using the Real time data to recommend touristic objectives depending on the current position of the user.

- Enriching user experience with the implementation within the application of Augmented Reality components.

- The inclusion of those algorithms that allow the subsequent analysis of data generated by tourists during the visit of an objective. This information will be useful to those who manage the objective and with their help, they will be able to predict the behavior and needs of tourists and they will be able to take measures to improve the visitor experience.

- Tourist applications, such as those using the Global Positioning System (GPS), are resource-consuming, so solutions must be found for tourists to be able to recharge their phones.

Our analysis reflects the authors' points of view, formed through the lenses of scientific literature investigations. Nevertheless, the value of an application and its degree of Smartness is given by the user. Therefore, our recommendations for improvement should be considered as a starting point for future quantitative research surveying the appropriateness of changes along the recommended lines.

\section{Acknowledgment}

The authors thank the anonymous reviewers and editor for their valuable contribution.

\section{Funding}

This work was co-financed from the European Social Fund through Operational Programme Human Capital 2014-2020, project number POCU/380/6/13/125015 "Development of entrepreneurial skills for doctoral students and postdoctoral researchers in the field of economic sciences".

\section{Author Contributions}

This study is the independent work of the two authors, from the conception of the topic to the literature review, data collection, and analysis. The authors equally participated in the making of this paper.

\section{Disclosure Statement}

The authors declare no conflict of interest. The funders had no role in the design of the study, in the writing of the manuscript, nor in the decision to publish the results.

\section{References}

1. Al-Turjman, F., (Ed.), (2019), Artificial Intelligence in IoT, Springer

80 Ssciendo


Sabou, G.C., Maiorescu, I., (2020)

The challenges of Smart Tourism: a case of Bucharest

2. Bucharest City App, (2020), Bucharest City App, Retrieved from: https://bucharestcityapp.com Accessed on 13 February 2020

3. Buhalis, D., Amaranggana, A., (2015), Smart tourism destinations enhancing tourism experience through personalisation of services, In Information and communication technologies in tourism 2015, Springer, Cham, 377-389

4. Brandt, T., Bendler, J., Neumann, D., (2017), Social media analytics and value creation in urban smart tourism ecosystems, Information \& Management, 54(6), 703-713, doi: 10.1016/j.im.2017.01.004

5. Campanaro, D.M., Landeschi, G., Dell'Unto, N., Touati, A.M.L., (2016), 3D GIS for cultural heritage restoration: A 'white box' workflow, Journal of Cultural Heritage, 18, 321-332, doi: 10.1016/j.culher.2015.09.006

6. Demir, Ö.F., Karaarslan, E., (2018), Augmented reality application for smart tourism: Gökovar, in $2018-6^{\text {th }}$ International Istanbul Smart Grids and Cities Congress and Fair (ICSG), 164-167), IEEE

7. Demunter, C., (2017), Tourism statistics: early adopters of big data? Retrieved from: https://ec.europa.eu/eurostat/documents/3888793/8234206/KS-TC-17-004EN-N.pdf, Accessed on 20 February 2020

8. European Capital of Smart Tourism, (2020), European Capital of Smart Tourism 2019 Retrieved from: https://smarttourismcapital.eu/downloads/guide-forapplicants.pdf, Accessed on 18 February 2020

9. Gavalas, D., Konstantopoulos, C., Mastakas, K., Pantziou, G., (2014), Mobile recommender systems in tourism, Journal of Network and Computer Applications, 39, 319-333, doi: 10.1016/j.jnca.2013.04.006

10. Google Play, (2020a), Google Play, Retrieved from:

https://play.google.com/store/apps/details?id=com.questo.questoapp\&hl=ro,

Accessed on 18 February 2020

11. Google Play, (2020b), Google Play, Retrieved from:

https://play.google.com/store/apps/details?id=de.topobyte.apps.offline.stadtplan.lit e.bucharest\&hl=ro, Accessed on 27 February 2020

12. Intersoft Consulting, (2020), GDPR, Retrieved from: https://gdpr-info.eu/, Accessed on 18 February 2020

13. Kontogianni, A., Alepis, E., (2020), Smart Tourism: State of the art and literature review for the last six years, Array, 6, 100020, doi: 10.1016/j.array.2020.100020

14. Lee, C.I., Hsia, T.C., Hsu, H.C., Lin, J.Y., (2017), Ontology-based tourism recommendation system, in $2017-4^{\text {th }}$ International Conference on Industrial Engineering and Applications (ICIEA), 376-379, IEEE

15. Li, Y., Hu, C., Huang, C., Duan, L., (2017), The concept of smart tourism in the context of tourism information services, Tourism Management, 58, 293-300 
Sabou, G.C., Maiorescu, I., (2020)

The challenges of Smart Tourism: a case of Bucharest

16. Nam, K., Dutt, C.S., Chathoth, P., Khan, M.S., (2019), Blockchain technology for smart city and smart tourism: latest trends and challenges, Asia Pacific Journal of Tourism Research, 1-15, doi: 10.1080/10941665.2019.1585376

17. Smart Tourism, (2020), Smart Tourism. Retrieved from:

http://www.smarttourism.org/, Accessed on 20 February 2020

18. Questo (2020), Bucharest Tours by Local Storytellers | Questo Walking Tours, Retrieved from: https://www.questoapp.com/city-games/bucharest-walking-tours, Accessed on 2 March 2020

19. Xiang, Z., Fesenmaier, D.R., (2017), Big data analytics, tourism design and smart tourism, in Analytics in smart tourism design, 299-307, Springer, Cham.

20. Yang, Q., (2018), A novel recommendation system based on semantics and context awareness, Computing, 100(8), 809-823, doi: 10.1007/s00607-018-0627-4 21. Zhang, L., Yang, H., Zhang, C., Li, N., (2018), A New Way of Being Smart?, Creative Computing and Its Applications in Tourism, in 2018 IEEE $42^{\text {nd }}$ Annual Computer Software and Applications Conference (COMPSAC) (Vol. 2, 45-50), IEEE 